\title{
Correlation of Computed Tomography findings with Glassgow Coma Scale in patients with acute traumatic brain injury
}

\section{Sah SK ${ }^{1}$, Subedi ND², Poudel K ${ }^{3}$, Mallik $\mathbf{M}^{1}$}

${ }^{1}$ Lecturer, ${ }^{3}$ Assist. Professor, Department of Radiology, Chitwan Medical College, Bharatur, Nepal, ${ }^{2}$ Lecturer, Dept of Forensic Medicine and Toxicology, College of Medical Sciences, Bharatpur, Nepal

\section{ABSTRACT}

\section{OBJECTIVE}

To correlate Computed Tomography (CT) findings with Glasgow Coma Scale (GCS) in patients with acute traumatic brain injury attending in Chitwan Medical College teaching hospital Chitwan, Nepal.

\section{MATERIALS AND METHODS}

A cross-sectional study was performed among 50 patients of acute (less than 24 hours) cases of craniocerebral trauma over a period of four months. The patient's level of consciousness (GCS) was determined and a brain CT scan without contrast media was performed. A sixth generation General Electric (GE) CT scan was utilized and $5 \mathrm{~mm}$ and $10 \mathrm{~mm}$ sections were obtained for infratentorial and supratentorial parts respectively.

\section{RESULT}

The age range of the patients was 1 to 75 years (mean age $35.6 \pm 21.516$ years) and male: female ratio was 3.1:1. The most common causes of head injury were road traffic accident (RTA) (60\%), fall injury (20\%), physical assault (12\%) and pedestrian injuries (8\%). The distribution of patients in accordance with consciousness level was found to be $54 \%$ with mild TBI (GCS score 12 to 14), 28\% with moderate TBI (GCS score 11 to 8 ) and 18\% with severe TBI (GCS score less than 7). The presence of mixed lesions and midline shift regardless of the underlying lesion on CT scan was accompanied by lower GCS.

\section{CONCLUSION}

The presence of mixed lesions and midline shift regardless of the underlying lesion on CT scan were accompanied with lower GCS. Patients having single lesion had more GCS level than mixed level and mid line shift type of injury.

\section{Keywords: Glassgow coma scale, traumatic brain injury.}

Correspondence: SK Sah

Email: sanjaysah21@yahoo.com 


\section{INTRODUCTION}

Trauma is a major health problem and is a leading cause of death in the age group 1 to 45 years. Head injuries cause or contribute to death in most trauma fatalities. Motor vehicle accidents (MVAs) are the leading cause of head injury followed by falls, assaults, firearm wounds and others. ${ }^{1,2,3}$ Traumatic brain injury constitutes one of the main health problems worldwide, currently with a high and increasing incidence, representing an important cause of mortality among adolescents and young adults.

The invention of CT in 1973, revolutionized the management of patients with acute cranio-cerebral trauma. ${ }^{4,5}$ The primary goal of imaging the trauma patient is to quickly and accurately identify treatable lesions before secondary injury to the brain occurs. CT is ideally suited to evaluate patients immediately after trauma. It is widely available, and rapid, permits close monitoring of unstable patients. It is very sensitive in detecting acute hematomas and depressed fractures that require emergency surgery.

The initial assessment of a patient with TBI includes the GCS, data regarding the accident and CT. It is essential to determine the cause of the trauma, the impact intensity, presence of neurological symptoms, convulsion, and particularly document any reports on loss of consciousness, ${ }^{6}$ time elapsed between the accident and the examination, vomits and seizures. ${ }^{7}$

According to the GCS, traumatic brain injuries are classified as mild, moderate or severe. The GCS was initially described by Teasdale \& Jennet in 1974, and is currently the most widely used parameter for assessment of consciousness level, as amongst its advantages, it comprises a set of very simple and easyto-perform physical examinations. ${ }^{8}$

CT findings in TBI vary according to the trauma severity, that is, in accordance with the GCS score.
The relationship among types of brain lesions demonstrated in CT, type of TBI(severity of the lesion) and prognosis are described by several authors in the literature ${ }^{9,10}$ all of them reporting approximately the same variation: the more severe the TBI is, more numerous and severe are the findings in CT.

Lower GCS and special CT scan findings including $\mathrm{SAH}$, midline shift of more than $3 \mathrm{~mm}$, and mass lesions are poor prognostic indicators after closed head injury. ${ }^{11}$ This study was oriented to determine the mechanisms, severity, and CT scan findings of head trauma and to evaluate the relation between CT scan findings and level of consciousness.

\section{MATERIALS AND METHODS}

It is a cross-sectional study conducted in the department of Radiology and Imaging, Chitwan Medical College (CMC) and Teaching Hospital, Bharatpur, Nepal. All cases that were referred for CT scan with acute cranio-cerebral trauma amongst the admitted patients at CMC from March to June, 2012 were studied. Known hypertensive and diabetic patients receiving anti-coagulant drugs, patients with known bleeding disorder and those with history of previous cerebro-vascular accident were excluded.

\section{STUDY METHOD}

The patients were scanned using GEBRIGHT SPEED helical CT machine. It is sixth generation CT scanner, matrix size-512, and slice thickness- $10 \mathrm{~mm}, 5 \mathrm{~mm}$, $3 \mathrm{~mm}, 2 \mathrm{~mm}$ and $1 \mathrm{~mm}$, having $\mathrm{KV}$ of 80 to 130 and mAs 50 to 340 .

A complete clinical history of the patients was taken. The type of trauma was classified into road traffic accident, falls, assaults, and pedestrian injury. This was 
Sah SK et al., Correlation of Computed Tomography findings.

followed by general physical examination and detailed examination of the central nervous system. Injuries involving the other systems of the body were also noted. After initial resuscitation, severity of cranio-cerebral trauma was graded with the help of GCS as follows:

\section{Grades}

Normal

Mild head injury

Moderate head injury

Severe head injury

The patients were examined with $\mathrm{CT}$ scanner in the supine position having gantry tilt $+/-25$ degree parallel to the scan plane to the orbito-meatal line. The scan range included base of skull to the vertex.

The data was analyzed by SPSS (Statistical Package for software analysis) version 17.0. The correlation between $\mathrm{CT}$ scan findings and the level of consciousness was evaluated using chi square test. Independent sample $t$ test was used to study the number of lesions and presence of midline shift with mean GCS. P value $<0.05$ was regarded as significant.

\section{RESULTS}

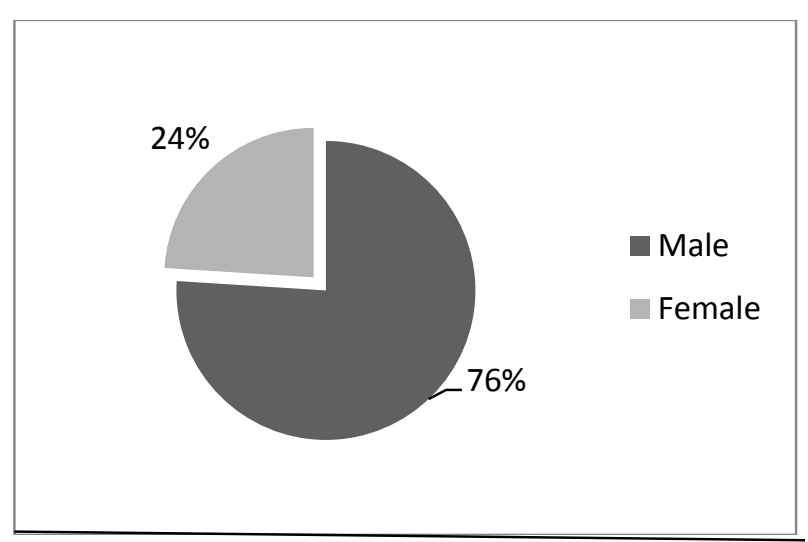

Fig. No. 1: Sex distribution of cases In the present study, as shown in figure 1 , males were predominant comprising of
$76 \%$ cases and $24 \%$ females resulting male: female ratio of 3.1:1. The age and sex distribution of the cases is represented by table 2 .

TABLE 2: SEX AND AGE DISTRIBUTION

\section{OF CASES}

\begin{tabular}{|c|c|c|c|c|c|}
\hline \multirow[b]{2}{*}{$\begin{array}{l}\text { AGE } \\
\text { (years) }\end{array}$} & \multicolumn{2}{|c|}{ MALE } & \multicolumn{2}{|c|}{ FEMALE } & \multirow[b]{2}{*}{$\begin{array}{l}\text { TOTAL } \\
\text { NO }\end{array}$} \\
\hline & No & $\%$ & No & $\%$ & \\
\hline $0-10$ & 5 & 13.16 & 4 & 33.34 & 9 \\
\hline $11-20$ & 5 & 13.16 & 0 & 00 & 5 \\
\hline $21-30$ & 3 & 7.89 & 1 & 8.33 & 4 \\
\hline $31-40$ & 9 & 23.69 & 1 & 8.33 & 10 \\
\hline $41-50$ & 10 & 26.32 & 3 & 25 & 13 \\
\hline $51-60$ & 2 & 5.26 & 0 & 00 & 2 \\
\hline 61-70 & 2 & 5.26 & 2 & 16.67 & 4 \\
\hline$>70$ & 2 & 5.26 & 1 & 8.33 & 3 \\
\hline TOTAL & 38 & 100.00 & 12 & 100.00 & 50 \\
\hline
\end{tabular}

\section{TABLE 3: INCIDENCE OF DIFFERENT} MODES OF INJURY

$\begin{array}{lll}\begin{array}{l}\text { TYPE } \\ \text { INJURY }\end{array} & \begin{array}{l}\text { NO.OF } \\ \text { CASE }\end{array} & \text { PERCENTAG } \\ \text { S } & \\ \text { RTA } & 30 & 60.00 \\ \text { Fall } & 10 & 20.00 \\ \begin{array}{l}\text { Physical } \\ \text { assault }\end{array} & 06 & 12.00 \\ \begin{array}{l}\text { Pedestrain } \\ \text { S }\end{array} & 04 & 8.00 \\ \text { TOTAL } & 50 & 100.00\end{array}$

In our study, the commonest mode of injury was RTA in $60 \%$ cases, followed by falls in $20 \%$, assaults in $12 \%$ and pedestrian injury in $8 \%$ (Table 3 ). 
Sah SK et al., Correlation of Computed Tomography findings

Table No. 4: Granding of type of lesions based on GCS

$\begin{array}{lccc}\text { CTFindings } & \text { No } & \text { Mean GCS } \pm \text { SD } & \text { Pvalue } \\ \text { Single lesions } & 27 & 13.33 \pm 1.330 & <0.001^{*} \\ \text { Multiple lesion } & 14 & 10.50 \pm 1.990 & <0.001^{*} \\ \begin{array}{l}\text { Single lesion + } \\ \text { Multiple lesion+ } \\ \text { Midline Shift }\end{array} & & & \\ \text { * } & & & \\ \text { *ighly significant at95\% CI } & & \end{array}$

The mean GCS was compared with the cases with single and multiple lesions and, lesions with midline shift using independent samples $t$ test. The mean GCS of the cases with single lesion was $13.33 \pm 1.330$ and that of those with multiple lesions was $10.50 \pm 1.990$. Their mean GCS was statistically significant ( $\mathrm{p}$ value $<0.001)$.

The mean GCS of the cases with multiple lesions and those with multiple lesions with midline shift (mean \pm SD of $6.22 \pm 1.202$ ) was also statistically significant ( $\mathrm{p}$ value $<0.001$ ).

While analysing the type of lesion within association of GCS score, it was revealed that

(a) Multiple lesions have lower GCS score than single lesion.

(b) Midline shift + multiple lesions have lower GCS score than single lesion and multiple lesion.
Table No. 5: Grading of head injury based on GCS score

$\begin{array}{lccc}\begin{array}{l}\text { Type of } \\ \text { head injury }\end{array} & \text { GCS } & \begin{array}{l}\text { No.of } \\ \text { cases }\end{array} & \text { Percentage } \\ \text { MILD } & 12-14 & 27 & 54 \% \\ \text { MODERATE } & 8-11 & 14 & 28 \% \\ \text { SEVERE } & <7 & 9 & 18 \% \\ \text { TOTAL } & & 50 & 100 \%\end{array}$

According to the GCS grading, there were $54 \%$ mild head injury cases, $28 \%$ moderate cases and $18 \%$ severe cases (Table 6).

\section{DISCUSSION}

Early and precise determination of cranio-cerebral lesions in acute head trauma is of great importance because of the high mortality caused by these lesions and the fact that early diagnosis and treatment will significantly reduce the complications. CT scan is now the primary modality for evaluation of patients with acute head trauma. An important factor in decision making about the initial treatment and long term complications is the initial GCS of patients.

It is universally noted that the cranio-cerebral trauma is more frequent in the males Male predominance varies from $81 \%$ in England, to as low as 59\% in the United States as reported by Kalsbeek and associates. ${ }^{12}$ Male predominance was also seen in the present study where Male: Female ratio was 3.1:1. 
Head injuries are more frequent in the younger age group in the United States. The incidence of head injury in 0-20 age group was 30\%, 20-40 years was $60 \%$ and above 40 years was $10 \% .{ }^{12}$ In the present study also the incidence of cranio-cerebral trauma was highest in the age group 41-50 which was $26 \%$.

According to Lindell, ${ }^{1}$ the incidence of RTA was 20$50 \%$. But in the present study it was found that the incidence of RTA was high i.e.60\%. This can be attributed to the reason that participants in this study live in close proximity to the National Highway and due to rapid urbanization in this area there is an increase in the number of vehicles and population leading to more movement of people.

CT scan findings and their correlation with GCS scores is especially important in treatable lesions like mass effects, brain herniation etc. These secondary lesions can cause significant morbidity and mortality.

In the present study, low GCS scores were considered as a severity risk factor in association with a greater number of tomographic findings. Patients with TBI and low GCS scores are affected by cerebral injuries with more devastating effects and present with a tendency for hemodynamic instability as observed in other studies.

Patients having mixed lesions and midline shift had low GCS score than the patients having single lesion. Mild head injury patients have 12 to 14 GCS score, moderate head injury patients 8 to 11 and severe head injury patients less than 7 . So, we conclude that severe the head injury lowers the Glassgow Coma Scale.

\section{CONCLUSION}

The presence of mixed lesions and midline shift regardless of the background lesions was significantly related to decrease in GCS score in patients. More severe the head injury lesser the GCS score.

\section{REFERENCES}

1. Hryshko FG, Deeb ZL. Computerized tomography in acute head injuries. J. Comput. Assist Tomogr 1983;7:331-44.

2. Gentry LR. Imaging of closed head injury. Radiology1994;191:1-17.

3. Kalsbeek WD, McLaurin RL, harris BSH, et al. The national head and spinal cord injury survey: Major findings. J Neurosurg 1980;53:519-31.

4. Ambrose J. Computerized transverse axial scanning (Tomography): Clinical Approach. Brit J Radiol 1974;46:679-95.

5. Hounsfield GN. Computerized transverse axial scanning (Tomography): Description of System. Brit J Radiol 1973;16:1016-22.

6. Serra ACV, Serra LSM. Swallowing aspects in traumatic brain injury patients. Revesta CEFAC. Available at: http://www.revistacefac.com.br/ fasciculo.php?form=edicoes/v8n1.php. Accessed Feb 14, 2014.

7. Nitrini R, Bacheschi LA. A neurologia que todo médico deve saber. São Paulo: Editora Maltese 1993. 
Sah SK et al., Correlation of Computed Tomography findings.

8. Teasdale G, Jennett B. Assessment of coma and impaired consciousness: a practical scale. Lancet 1974;2:81-4.

9. Gennarelli TA, Spielman GM, Langfitt TW, et al. Influence of the type of intracranial lesion on outcome from severe head injury. J Neurosurg 1982; 56:26-32.
10. Wardlaw JM, Easton VJ, Statham P. Which CT features help predict outcome after head injury? J Neurol Neurosurg Psychiatry 2002;72:188-92.

11. Youmans J. Neurological Surgery.5th edition. Philadelphia: WB Saunders 2004: 5019-5273.

12. Kalsbeek WD, McLaurin RL, Harris BS et al. The national head and spinal cord injury survey: Major findings. J Neurosurg 1980;53:519-31. 